\title{
The Application of Passive Air Jet Vortex-generators to Stall Suppression on Wind Turbine Blades.
}

\author{
Simon A. Prince ${ }^{1}$, Carmine Badalamenti ${ }^{2}$, Constantinos Regas ${ }^{2}$ \\ ${ }^{1}$ Cranfield University, School of Engineering, Cranfield, Bedfordshire, MK43 OAL \\ ${ }^{2}$ City University London, School of Engineering \& Mathematical Sciences, Northampton Square, London EC1V OHB, UK.
}

\begin{abstract}
An experimental study was performed to assess the feasibility of passive air jet vortex-generators (AJVGs) to the performance enhancement of a domestic scale wind turbine. It has been demonstrated that these simple devices, properly designed and implemented, can provide worthwhile performance benefits for domestic wind turbines of the type investigated in this study. In particular, this study shows that they can increase the maximum output power coefficient, reduce the cut-in wind speed and improve power output at lower wind speeds, while reducing the sensitivity to wind speed unsteadiness. A theoretical performance analysis of a $500 \mathrm{~kW}$ stall regulated wind turbine, based on Blade Element Momentum Theory, indicates that passive AJVGs would be capable of recovering some of the power loss due to blade stall, thereby allowing attainment of rated power output at slightly lower average wind speeds.
\end{abstract}

\section{Keywords}

Passive flow control, vortex-generators, aerodynamics, stall suppression

\section{Nomenclature}

$\begin{array}{ll}c & \text { aerofoil/blade chord }(m) \\ \mathrm{C}_{\mathrm{A}} & \text { axial force coefficient } \\ \mathrm{C}_{D} & \text { drag coefficient } \\ C_{L} & \text { lift coefficient } \\ C_{M} & \text { quarter chord pitching moment coefficient } \\ C_{\mu} & \text { air jet blowing momentum coefficient }\left(\dot{m} \overline{u_{j}} /(q S)\right) \\ C_{N} & \text { normal force coefficient } \\ C_{p} & \text { pressure coefficient } \\ C_{P} & \text { power coefficient } \\ C_{p t} & \text { trailing edge pressure coefficient } \\ \dot{m} & \text { mass flow rate through the jet }(\mathrm{kg} / \mathrm{s}) \\ q & \text { freestream dynamic pressure }(P a) \\ \operatorname{Re}_{c} & \text { Reynolds number based on chord }\end{array}$

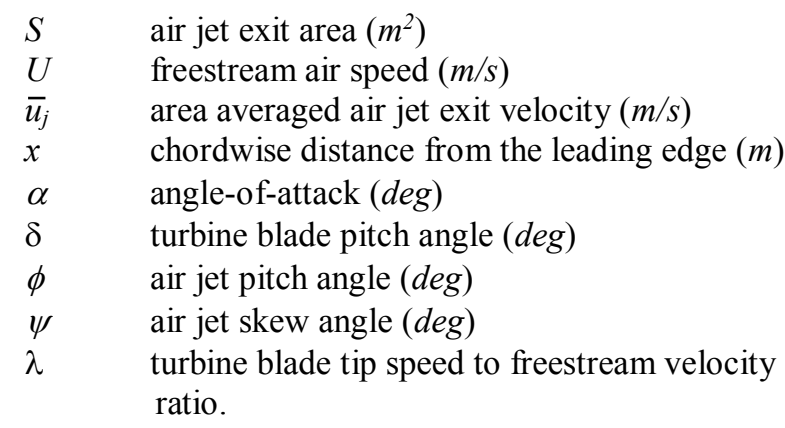

\section{INTRODUCTION}

Fixed pitch (stall regulated) wind turbines operate with the blades set at a constant pitch setting across the wind speed range, and can therefore be strongly affected by aerodynamic stall. Variable pitch (pitch regulated) control is employed on many industrial wind turbines such that the effect of aerodynamic stall is limited. For a given blade design, however, the maintenance of trailing edge separation, and thereby fully attached flow over the blade, cannot generally be achieved across the entire span for all wind speeds, even with variable pitch control. There will always be some range of wind speed where a wind turbine blade will, to some extent, be affected by localised boundary layer separation, particularly inboard on the blade.

While fixed pitch wind turbines are generally cheaper and simpler than their variable pitch counterparts, their power capture characteristics will be considerably poorer, especially at the higher wind speed range. Ideally one would like to achieve the power capture capability of a pitch regulated wind turbine, but with the mechanical simplicity of a stall regulated version.

Numerous studies have been undertaken to investigate flow control devices for the suppression of trailing edge separation and subsequent aerodynamic stall on aerofoil elements. Figure 1 presents the typical power curve for a $250 \mathrm{~kW}$ stall regulated wind turbine with standard (clean) blades compared with the corresponding power curve expected with the application of an effective stall suppression flow control system, which would be able to recover much of the power lost to aerodynamic stall. The power curve with flow control would therefore be much closer to that expected of a corresponding pitch regulated wind turbine. 
In cases where there are significant stall effects at low wind speeds, where the Reynolds number is low, stall suppression devices could reduce the cut-in wind speed, allowing the wind turbine to generate some power at lower wind speeds.

Naturally occurring flow separation caused by surface curvature can be delayed by the inherent mixing in turbulent boundary layers. Natural turbulent flow exhibits an effective self-mixing and transport mechanism but generally cannot, on its own, transfer enough momentum into the boundary layer to prevent flow separation in adverse pressure gradients. In order to delay the departure of the boundary layer from a surface, artificial flow mixing enhancement devices can be used to re-energize the boundary layer by increasing the kinetic energy of the low momentum near-wall fluid.

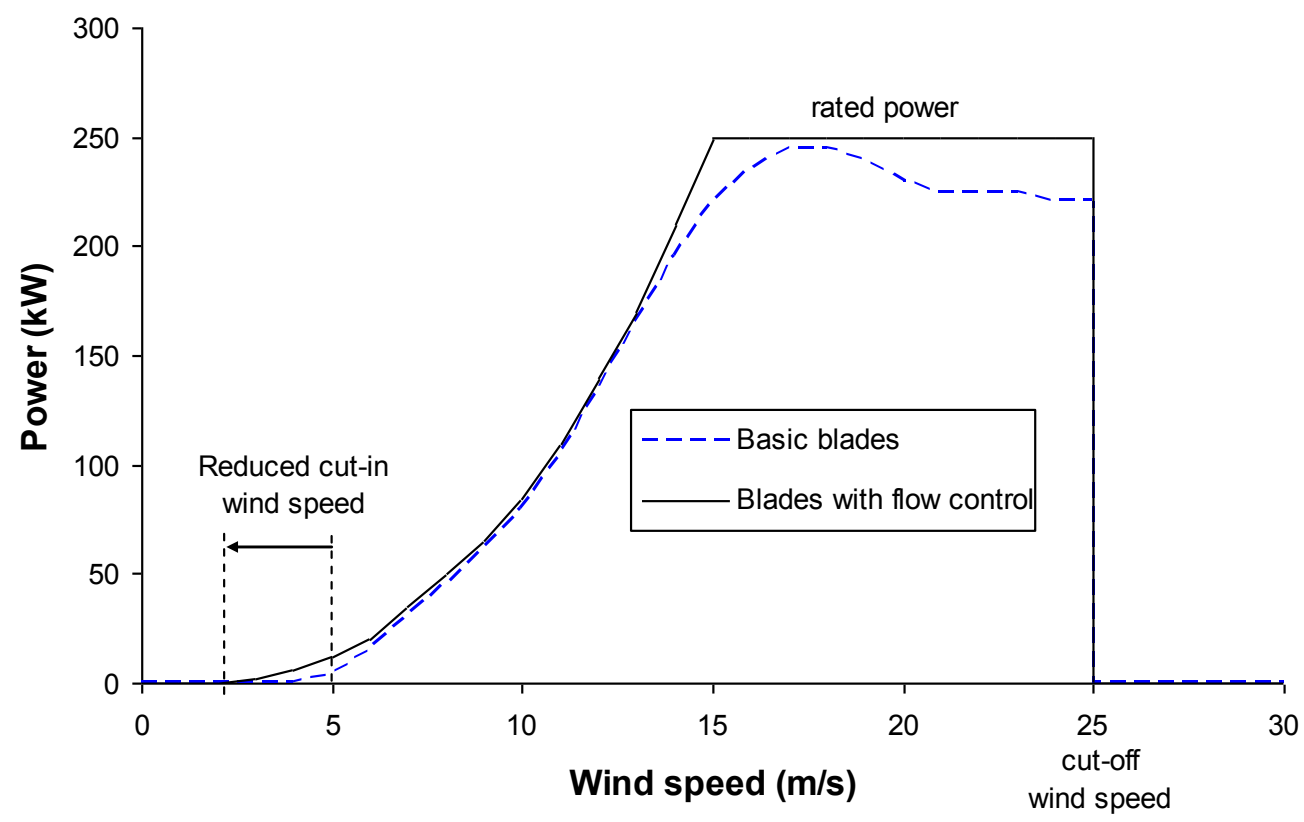

Figure 1: The effect of stall suppression flow control on a wind turbine power curve

\section{VORTEX-GENERATORS FOR WIND TURBINE PERFORMANCE ENHANCEMENT}

\subsection{Vane Vortex-generators}

Various flow control methods which aim to reenergise tired boundary layers and thereby suppress flow separation, have been successfully developed. These include techniques such as vane vortex-generators ${ }^{1}$, steady air jet blowing ${ }^{2-4}$, pulsed blowing ${ }^{5-9}$ and synthetic jets ${ }^{10-15}$. The technique of intensifying the fluid mixing rates by the artificial formation of boundary layer embedded longitudinal vortices has been found to be a particularly powerful method. The vortices act to entrain high-energy flow from the undisturbed outer air stream and transport it into the low momentum near-wall region deep inside the boundary layer. The first separation suppression devices investigated were classical vane type vortex-generators. These passive, mechanical vane vortex-generators, devised by Taylor and Hoadley ${ }^{1}$ generally consist of thin solid vanes fixed to the surface, usually positioned ahead of a separated flow region, at an angle to the on-coming flow. However, it has been demonstrated that vane vortex-generators impose a drag increase, arising from the local pressure increase due to the protrusion of the vane itself, and by an increase in surface skin friction underneath the resulting streamwise vortex.

Vane vortex-generators were first installed on the NASA/DOE Mod-2, 2.5MW two-bladed, partial-span, tip controlled, pitch regulated wind turbine by Boeing ${ }^{16}$. Sullivan ${ }^{17}$ investigated vane vortex-generators on this $91.44 \mathrm{~m}$ diameter rotor blade, to improve power conversion performance as well as to improve drive train stability. The vortex-generators were arranged in a counter-rotating system. Applying vane vortex-generators from $20 \%$ span to the tip resulted in projected increases in annual energy capture of $20 \%$ and reduced the wind speed to achieve rated power by nearly $3 \mathrm{~m} / \mathrm{s}$. Applying vortex-generators only on the inboard section resulted in performance improvements of only half of this.

Corrigan and Savino ${ }^{18}$ applied vane vortex-generators to the NASA Mod-0, $100 \mathrm{~kW}, 39 \mathrm{~m}$ diameter wind turbine to investigate their potential to improve aerodynamic performance. Vortex-generators, in a counter-rotating vortex system, were fitted to the turbine blade tip section (outer $7.31 \mathrm{~m}$ ) and tested in full-scale wind tunnel tests. Analysis of the wind tunnel results indicated that the net force in the plane of rotation could be increased by up to $30 \%$ upon installation of vane vortex-generators at full-scale. Once tested in the field, it was shown that a maximum of $30 \%$ increased power output could be achieved for wind speeds above $6 \mathrm{~m} / \mathrm{s}$.

Gyatt ${ }^{19}$ undertook field tests on the $77 \mathrm{~m}$ diameter Carter 25, two-bladed wind turbine employing a counter-rotating array of vane vortex-generators for performance improvement. In this case performance improvement amounted to only a $6 \%$ increase in energy production at mean wind speed of $23.5 \mathrm{~m} / \mathrm{s}$. Importantly, it was shown that the blades were very susceptible to bugs and 
dirt on the leading edge. The vortex-generators were found to reduce significantly the sensitivity of blades to accumulation of this kind of leading edge roughness.

Subsequent analysis combining wind tunnel testing of blade sections and blade element momentum theory calculations by Garrard $^{20}$ indicated that, for a Howden and Co. HWP 330 turbine, even where quite large improvement in local $\mathrm{C}_{\mathrm{Lmax}}$ could be achieved with vortex-generators, only very small increases in energy yield of around $1 \%$ could be achieved. Garrard suggested that the very high levels of performance improvements seen in the early field tests could be attributed to a high sensitivity to dirt on the blade surfaces which probably resulted in local separations that were easily cleaned up by vortex-generators. The NACA 230xx profile of the Mod-2 was certainly found to be highly susceptible to dirt, and was later replaced by the GAW(1) profile. In support of this hypothesis, the computational model of the Mod-2 turbine of Afjeh et $\mathrm{al}^{21}$, which provided excellent prediction of the turbine performance with vortex-generators, over-predicted the power generated by the clean blades.

Nyland $^{22}$ employed the Mod-2 turbine and undertook experimental surface pressure measurements at a $33 \%$ span location. As expected, the vortex-generators were shown to change the shape of the pressure coefficient curves by increasing the peak values and delaying separation. $\varnothing \mathrm{ye}^{23}$ and Antoniou et $\mathrm{a}^{24}$ undertook field tests of the effect of vortex-generators on the performance of the Elkraft $1000 \mathrm{~kW}$ wind turbine. The basic version of this turbine was found to underperform, compared with design calculations, and even with a $0.5^{\circ}$ increase in blade pitch angle, the power capture was still some $6 \%$ below the design goal for a mean wind speed of $7 \mathrm{~m} / \mathrm{s}$. This was traced to flow separation on the very thick inboard sections of the blade, which was suppressed using an array of counter-rotating vane vortex-generators, resulting in recovery to design power output.

The results from these field tests of vane vortex-generators on full-scale wind turbines showed that their principle benefits are: 1) the suppression of flow separation from inboard thick sections, allowing the design of even thicker blade roots and much larger blades leading to machines of higher rated power, 2) the desensitisation of the flow to dirt accumulation, and 3) a reduction in the effects of dynamic stall related unsteady loading.

\subsection{Air Jet Vortex-generators}

An alternative to vane vortex-generators is an active fluid vortex-generating device, which was proposed by Wallace ${ }^{25}$. The idea was to use fluid injection via inclined and skewed (relative to the freestream flow) wall-bounded jets, to induce longitudinal vortices for flow control. Air jet vortex-generators (AJVGs) usually consist of an array of small orifices, embedded on a surface and supplied by a pressurized fluid source, wherein longitudinal vortices are induced by the interaction between the jets issuing from each orifice and the fluid flowing along the surface. Fluid mixing is promoted by the action of the vortices, and energisation of the boundary layer is also achieved through momentum injection into the lower layers of the boundary layer, much akin to the action of slot blowing and synthetic jets. The orifices are pitched with respect to the surface tangent and skewed with respect to the local fluid vector. AJVGs, unlike vane type vortex-generators, do not induce a large increase in drag at low $\alpha$, and can be actively operated and controlled, depending on the flow characteristics over a surface.

Oliver $^{26-28}$ conducted low speed wind tunnel experiments on a $17 \%$ thick NACA $63_{2} 217$ aerofoil model of $0.5 \mathrm{~m}$ chord. Experiments were performed at $U=35 \mathrm{~m} / \mathrm{s}$ and $R e_{c}=1.1 \times 10^{6}$ with a co-rotating array of AJVGs oriented at $30^{\circ}$ pitch and $60^{\circ}$ skew angle (which has been demonstrated to provide optimum vorticity generation in the boundary layer, and thereby mixing effect ${ }^{2}$ ), located on the upper surface at $10 \%$ chord. Each AJVG orifice was spaced at $0.1 c$ interval. Oliver showed that, while high mass flow rates produce the best performance, aerofoil stall could be effectively delayed (by up to $6^{\circ}$ angle-of-attack) with low blowing rates $(\mathrm{C} \mu<0.01)$, thereby increasing the maximum lift force by up to $50 \%$. These findings were confirmed by Vronsky ${ }^{29}$ with an AJVG array of similar design, applied to a $21 \%$ thick (NACA 63-421) aerofoil section model.

In addition to wind tunnel test results of AJVGs, Oliver ${ }^{27,28}$ reported results of a full-scale field test of fan powered AJVGs applied to an Ecotecnia 20/150 150kW wind turbine. This was done in order to increase the energy yield by reducing energy losses in the region of the power curve 'knee'. It was shown that the air jets were able to increase average power output from $85 \mathrm{~kW}$ to $95 \mathrm{~kW}$ at $12 \mathrm{~m} / \mathrm{s}$, and from $135 \mathrm{~kW}$ to $150 \mathrm{~kW}$ at $16 \mathrm{~m} / \mathrm{s}$, effectively straightening the power curve prior to the achievement of rated wind speed. Taking into account the energy required to run the fans, the estimated energy yield increase was from $1 \%$ at $7 \mathrm{~m} / \mathrm{s}$ to $2 \%$ at $10 \mathrm{~m} / \mathrm{s}$ average wind speed.

\subsection{The Passive Air Jet Vortex-generator}

A further development of the AJVG is the passive version reported by Prince et. al. ${ }^{30,31}$ and Krzysiak ${ }^{32}$. Here the relatively high pressure air from the attachment line region on the underside of the leading edge of a blade is induced, via carefully designed contoured intakes, to the air jet orifice on the upper surface by the suction that exists there, as shown in figure 2 . The passive AJVG embodies all of the benefits of the powered version but has the added benefit of requiring no additional energy input, operating purely by the action of the natural pressure difference between the attachment line and upper surface. 

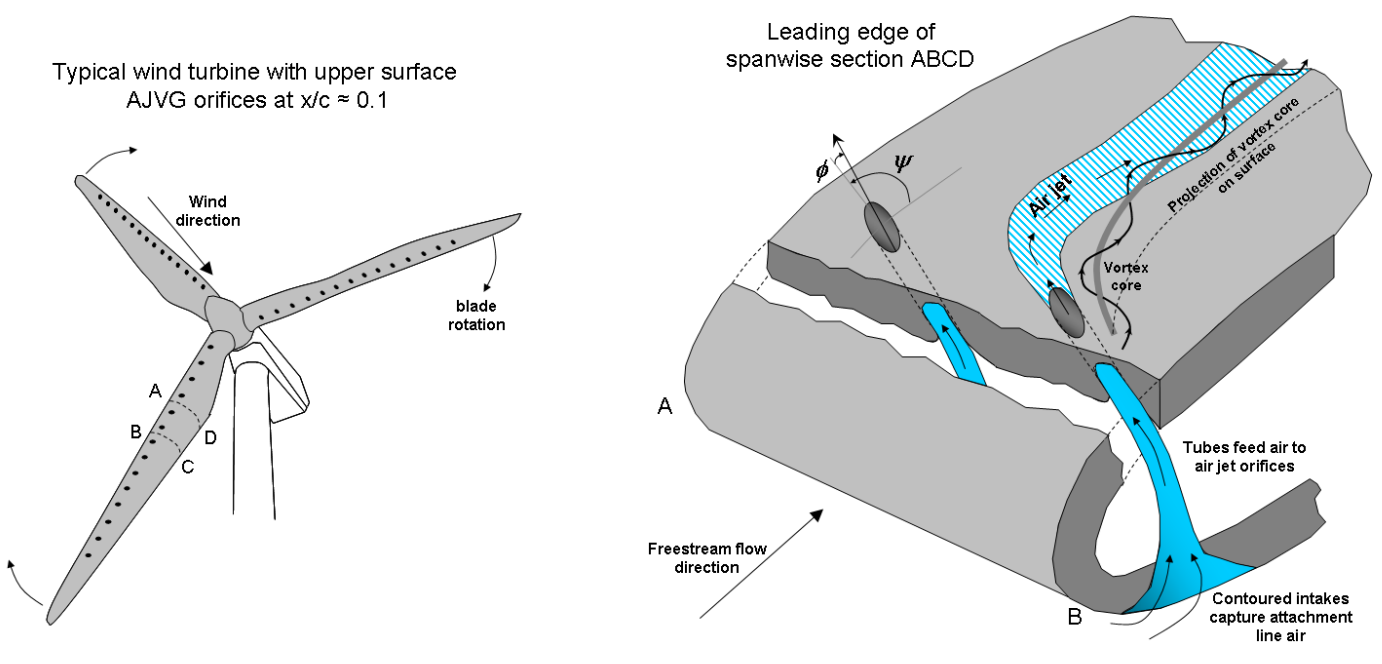

Figure 2: The passive AJVG concept for wind turbine blades

This paper presents results of an initial wind tunnel test of the passive AJVG on two representative aerofoils of the type used for the wind turbine blade root region, and for the outboard region near the tips, as a means to demonstrate their effect. Results are also presented from a wind tunnel test investigating their effect on a 6-bladed, $0.87 \mathrm{~m}$ diameter domestic wind turbine.

\section{TURBINE BLADE SECTION EXPERIMENTS}

\subsection{The models and experimental arrangements}

An initial experimental investigation was undertaken to assess the performance enhancements that might be gained by applying passive AJVGs to a NACA 23012C aerofoil blade section model, similar to the type used for the outboard section of a wind turbine blade, and also on a similar model with a NACA $63_{2} 217$ profile more typical of an inboard blade section. The first model employed the NACA 23012C section - a modification of the standard NACA 23012 having increased camber and a modified trailing edge to promote separation $\left(G_{r e e n}^{33}\right)$. The model, of $0.481 \mathrm{~m}$ chord and $0.74 \mathrm{~m}$ span, was fitted with a spanwise array of 15 passive air jets of $4.8 \mathrm{~mm}$ diameter circular orifices, located at $12 \%$ chord and spaced $45 \mathrm{~mm}$ apart. Smoothly curved $4.8 \mathrm{~mm}$ diameter steel tubes connected the orifices to contoured intakes ( $3 \mathrm{~mm}$ corner rounding) at $4 \%$ chord on the lower surface. The model was fitted with large end plates to enforce quasi-2D flow and with leading edge sand roughness transition strips. The air jet orifices were designed with $30^{\circ}$ pitch angle and $60^{\circ}$ skew angle to the local aerofoil surface and local flow direction respectively, as identified for maximum vorticity generation by Freestone ${ }^{2}$.

The second model used a NACA 632-217 section, and was constructed with an array of ten passive AJVGs. The model was of span $0.975 \mathrm{~m}$ and $0.8 \mathrm{~m}$ chord, and the AJVGs orifices (10 mm diameter) were located at $12 \%$ chord with $84 \mathrm{~mm}$ spanwise separation. Both models employed the same jet local pitch and skew angles.

Both models were instrumented with three parallel, chordwise arrays of 82 static pressure holes each, for the measurement of the surface pressure along chordwise planes passing through i) the centre of the orifice located on the centreline of the model, ii) the plane halfway in between this orifice and its adjacent orifice and iii) a plane half way in between these. The pressure holes were constructed from $0.5 \mathrm{~mm}$ (inner-diameter) brass tube embedded flush with the model surface. One of the pressure holes in each array was located at the trailing.

The momentum deficit through the wake was measured using a wake rake positioned one chord length downstream of the trailing edge. The rake consisted of 40 pitot probes and 5 static probes. The pitot pressure probes were spaced with $7 \mathrm{~mm}$ intervals in the centre portion and $15 \mathrm{~mm}$ intervals at the edge, having a total span of $350 \mathrm{~mm}$. The static pressure probes were used to capture static pressure gradients across the wake. These wake measurements, averaged between those taken on the span centreline as well as on a plane $20 \mathrm{~mm}$ off centre, were then used for the calculation of the form drag coefficient using the method of B.M.Jones ${ }^{34}$.

The pressures were acquired using a piezosensitive pressure measurement system. The accuracy of these pressure measurements is estimated to be $\Delta C p= \pm 0.02$ at a freestream speed of $35 \mathrm{~m} / \mathrm{s}$, and \pm 0.05 at $25 \mathrm{~m} / \mathrm{s}$. Spanwise time-averaged surface pressure distributions, obtained at rate of $320 \mathrm{~Hz}$ over $30 \mathrm{~seconds}$, were then integrated (trapezium rule) over the aerofoil surface to calculate the force and moment coefficients. From previous tests employing a similar density and distribution of surface pressure holes, the integrated normal force and pitching moments were found to be within 5\% of the six-component strain gauge balance measurements at zero degrees angle-of-attack, reducing to about $1 \%$ at higher angles-of-attack.

The NACA $23012 \mathrm{C}$ experiments were performed in the City University T2 low-speed wind tunnel across the wind speed range $15-35 \mathrm{~m} / \mathrm{s}\left(0.7 \times 10^{6}<R e_{c}<1.1 \times 10^{6}\right)$, while the NACA $63_{2}-217$ measurements were obtained in the City University T7 wind tunnel across the wind speed range $5-25 \mathrm{~m} / \mathrm{s}\left(0.27 \times 10^{6}<R e_{c}<1.3 \times 10^{6}\right)$. The models were pitched continuously in angle- 
of-attack while the freestream dynamic pressure was maintained constant. Solid blockage was estimated at a maximum of $14 \%$ for the highest angle-of-attack of $\alpha=30^{\circ}$. Accuracy of the geometric angle-of-attack measurements has been estimated at $\pm 0.5^{\circ}$.

\subsection{Results from the NACA23012C blade section tests}

A sample of the measured aerodynamic characteristics for the NACA23012C blade section are plotted in figure 3 for $U=35 \mathrm{~m} / \mathrm{s}, R e_{c}=1.1 \times 10^{6}$. Air jet exit conditions were measured using a small pitot probe traverse such that maximum $C_{\mu}$ was estimated at 0.0025 for $\alpha=18^{\circ}$ corresponding to a jet-to-freestream velocity ratio of 1.25 . Figures $3 \mathrm{a}$ ) -c) present a selection of the measured surface pressure distributions, comparing the results from the clean (sealed air jets) model and those with passive air jets operating, where the data from the array of pressure tappings in line with the jet orifice centre, and from that midway in between jet centres, are both plotted. For the three cases shown, the air jet effect is seen to be a suppression of trailing edge separation (indicated by negative $C_{p}$ at the trailing edge, and large plateau in upper surface $C_{p}$ ) and higher and more extensive leading edge suction. The lift curves for the clean aerofoil, and the passive air jet case, are compared in figure $3 \mathrm{~d}$ ). It can be seen that the passive air jets increased the maximum $C_{L}$ by about $14 \%$. Analysis of the trailing edge pressure coefficient showed that the air jets delayed the onset of trailing edge separation by $\Delta \alpha \sim 2^{\circ}$. The occurrence of lift stall, identified by maximum $C_{L}$, and pitching moment stall were also delayed by $\Delta \alpha \sim 2^{\circ}$ by the passive air jets. In the angle-of-attack range $14-22^{\circ}$ the passive air jets were found to have increased $C_{L}$ significantly which is indicative of the strength of leading edge suction. In addition there is seen, in figure $3 \mathrm{e}$ ), to be a corresponding reduction in nose up pitching moment coefficient. These effects are identical to those that would be expected of active air jets, blown at the same average $C_{\mu}$, but are achieved by a passive process with no active energy input. The comparison of the variation of drag coefficient, $C_{D}$, with angle-of-attack, is presented in figure $3 \mathrm{f}$ ). Here the dashed line at $\alpha=20^{\circ}$ indicates the limit of acceptable accuracy in the magnitude of drag coefficient, due to the wake at higher angles-of-attack being so extensive that the wake rake was no longer able to traverse its full extent. The authors had expected that a significant drag increase, at low $\alpha$, would occur with the introduction of the passive air jets, arising from a boundary layer displacement effect. The experimental evidence, however, did not support this hypothesis. The experimentally inferred drag coefficient at low angles-of-attack was not found to be significantly different with or without the passive air jets.

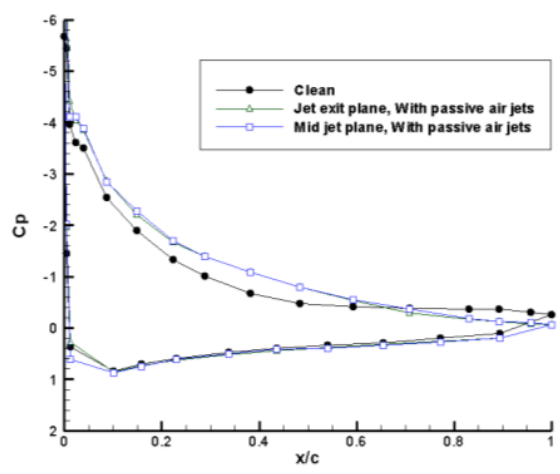

a) $C_{p}$ versus $x / c, \alpha=16^{\circ}$

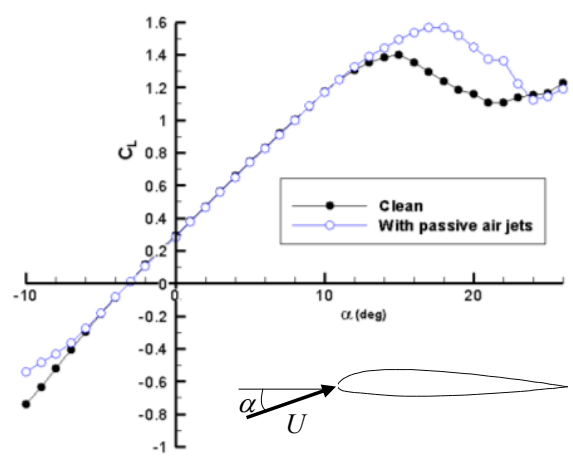

d) $C_{L}$ versus $\alpha$

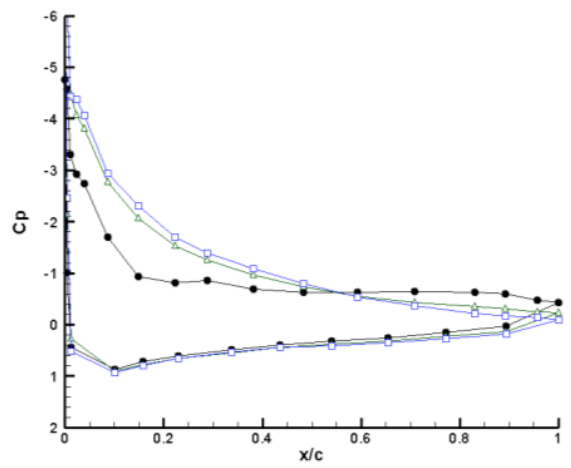

b) $C_{p}$ versus $x / c, \alpha=18^{\circ}$

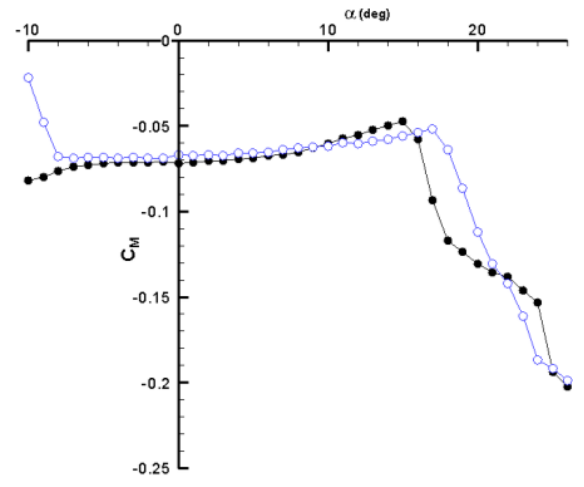

e) $C_{M}$ versus a

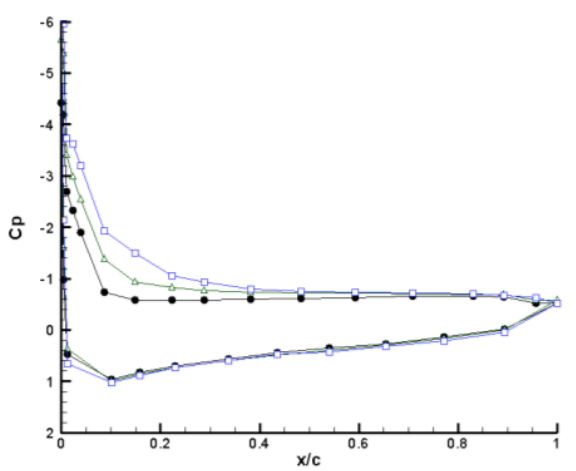

c) $C_{p}$ versus $x / c, \alpha=22^{o}$

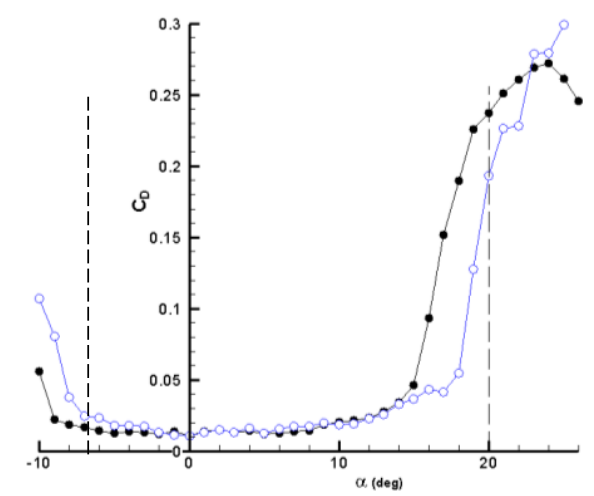

f) $C_{D}$ versus $\alpha$

Figure 3: Variation with incidence of the aerodynamic characteristics for $\mathrm{NACA} 23012 \mathrm{C}$ model at $U=35 \mathrm{~m} / \mathrm{s}, \mathrm{Re}_{c}=1.1 \times 10^{6}$. 


\subsection{Results from the NACA $63_{2} 217$ blade section tests}

A selection of the measured surface pressure data for the NACA $63_{2} 217$ section model is presented in figure $4 \mathrm{a}$ ) - c), where the $\mathrm{C}_{\mathrm{p}}$ distributions for the clean aerofoil case and that with open passive air jets are compared for angles-of-attack of 16,18 and $22^{\circ}$ for $U=25 \mathrm{~m} / \mathrm{s}\left(\operatorname{Re}_{c}=1.3 \times 10^{6}\right)$. The data for the passive air jet blowing case is the averaged pressure between that measured in line with the jet orifice centre, and at the same $x / c$ location, midway in between jet centres. In this case the air jets are also seen to suppress trailing edge separation, as indicated by the level of $\mathrm{C}_{\mathrm{p}}$ at the trailing edge and the extent of the rear pressure plateau. Comparison of the variation of the integrated pressure forces and moments for the NACA $63_{2} 217$ model is presented in figure $4 \mathrm{~d})$ - f) for the $25 \mathrm{~m} / \mathrm{s}$ wind speed case, and reveals that passive air jets have a similar enhancement effect on the aerodynamic characteristics on this thicker aerofoil section model. In this case the passive air jets have increased maximum $C_{L}$ by approximately $8 \%$, delaying stall by $\Delta \alpha \sim 3^{\circ}$. Pitching moment divergence was delayed by $\Delta \alpha \sim 2-3^{\circ}$. Figure $4 \mathrm{f}$ ) shows that, within the accuracy of the experimental instrumentation and numerical integration routine, there did not seem to be any appreciable effect of passive air jet blowing on drag coefficient at low angles-of-attack. Only small drag reductions, in the range $18-21^{\circ}$ angle-of-attack, were found.

These results, on statically pitched, unswept aerofoil models have confirmed that a spanwise array of passive AJVGs can delay effectively trailing edge separation, and the subsequent stall, to higher angles-of-attack, resulting in increased achievable $C_{L}$ while also delaying drag and pitching moment divergence. The passive AJVG, making use of a purely natural process, can achieve worthwhile aerodynamic performance improvements in such cases, but it remains to be demonstrated that these performance improvements can yield benefits with the unsteady and fully three-dimensional flows encountered by wind turbine blades. The next section presents the results of an experimental test of the passive AJVG applied to a domestic wind turbine.

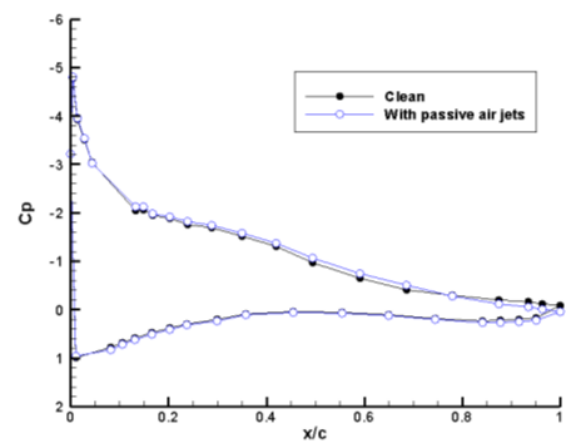

a) $C_{p}$ versus $x / c, \alpha=16^{\circ}$

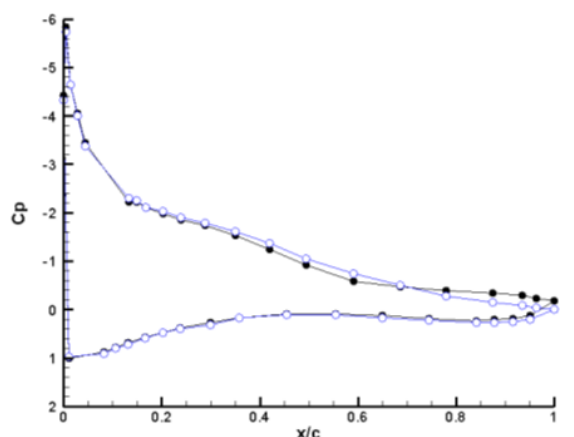

b) $C_{p}$ versus $x / c, \alpha=18^{\circ}$

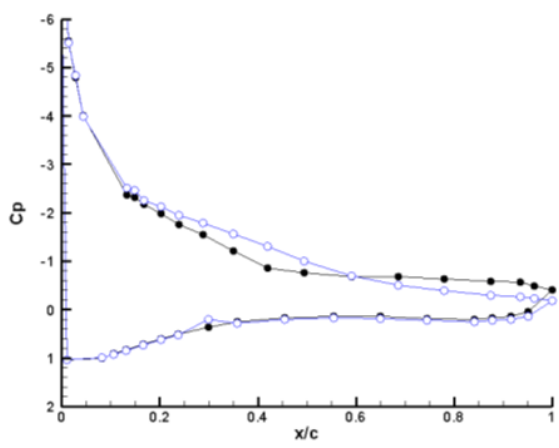

c) $C_{p}$ versus $x / c, \alpha=22^{\circ}$

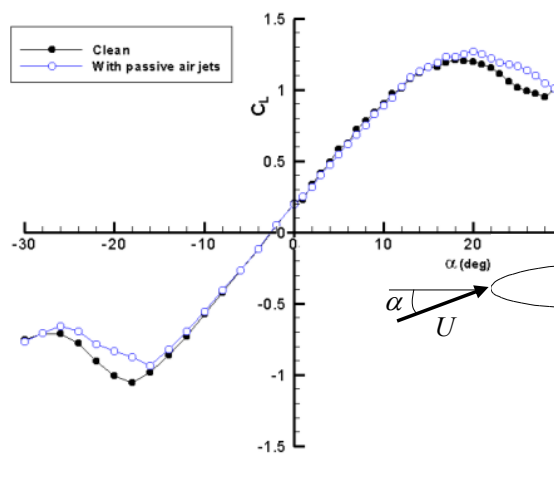

d) $C_{L}$ versus $\alpha$

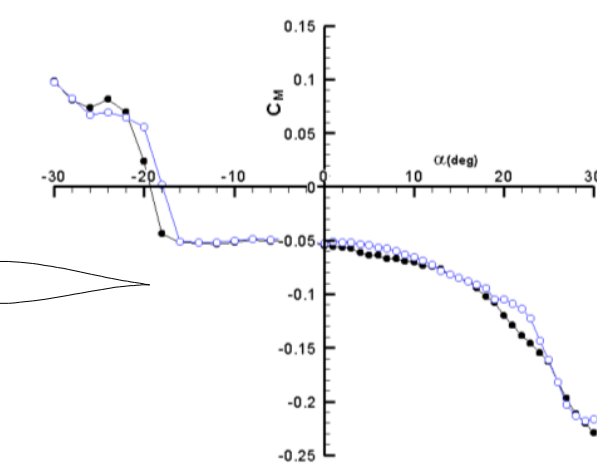

e) $C_{M}$ versus a

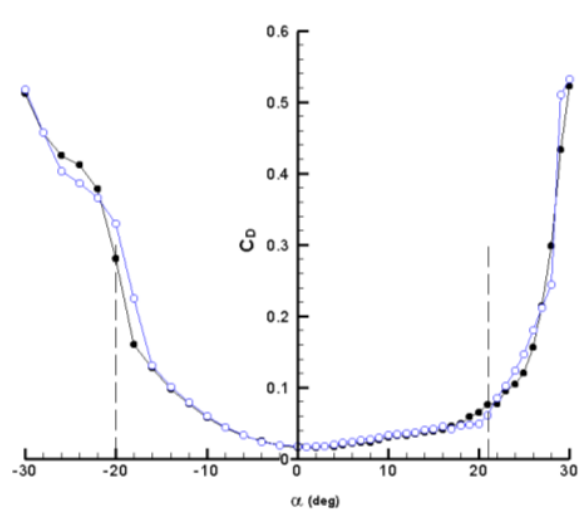

f) $C_{D}$ versus $\alpha$

Figure 4: Variation with incidence of the aerodynamic characteristics for $N A C A 63_{2} 217$ model at $U=25 \mathrm{~m} / \mathrm{s}, \operatorname{Re}_{c}=1.3 \times 10^{6}$.

\section{DOMESTIC WIND TURBINE TESTS}

\subsection{The test turbine and experimental arrangements}

The Aero4Gen-F 120W, 6-bladed, domestic wind turbine, manufactured by LVM Ltd. was used for this series of tests. The rotor has a swept diameter of $0.87 \mathrm{~m}$, with blade planform shown in figure 5 . The blade employs one aerofoil section with a twist of $15^{\circ}$ at the tip relative to the root. One set of six baseline blades was tested, and another separate set of six blades were modified to incorporate a spanwise array of 21 passive air jets. The $2 \mathrm{~mm}$ diameter jet orifice was set at the standard $30^{\circ}$ pitch 
and $60^{\circ}$ skew angle (where the jets were oriented outboard towards the tip), and were located in an array $10 \mathrm{~mm}$ from the leading edge chord line on the upper surface with the contoured inlets at about $5 \%$ chord on the lower surface.

The turbine employed the $12 \mathrm{~V}$ LVM412F generator rated at $120 \mathrm{~W}$ for a wind speed of about 20m/s which incorporates 3phase brushless alternators using a Neodymium-Iron-Boron permanent magnet rotor. The generator casing was modified to allow air blown cooling around the generator coils in order to eliminate any temperature variation effects.
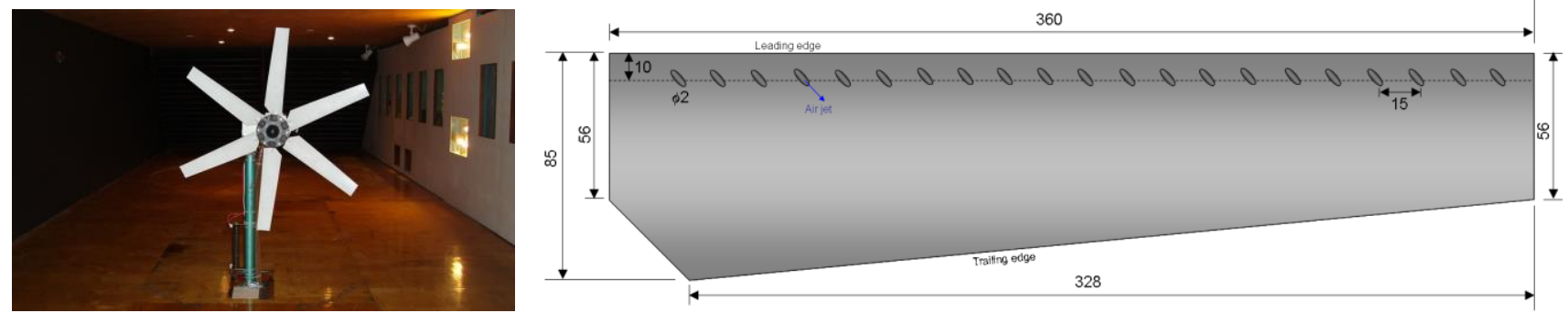

Figure 5: Aerogen Aero4Gen-F turbine and its blade geometry (upper surface planform view)

The turbine was mounted centrally in the working section of the City University T7 Wind Tunnel from a $2.5 \mathrm{~cm}$ diameter steel pole from which the turbine was fixed rigidly to face the wind stream. The voltage output from the generator was passed to a LabVIEW data acquisition system (DAQ) together with the tunnel dynamic pressure output from a FCO318 pressure transmitter. Two Ohmite wire-wound, vitreous enamel tube-type resistors, each rated at $2 \mathrm{~W}$ and $300 \mathrm{~W}$, were placed in series with the generator to act as the load. The specific choice of load resistance $\mathrm{R}=4 \Omega$ was made with the intention to restrain the rotational rate of the turbine at high wind speeds to protect against structural vibration.

The speed of rotation of the turbine during the experiments was determined by employing four steel screws that were used to fix the turbine to the generator's shaft as inputs to an IMO-M12-PNP 3-wire inductive proximity switch that was mounted on the generator's outer shell. With rotation of the turbine, the passing of the mounting screws by the location of the proximity switch caused it to produce a series of pulses, the rising edges of which were counted using the in-built capabilities of the DAQ system to determine the frequency of rotation. Power for the proximity switch was supplied by an EZ-GP4303D DC variable power supply set to provide $10 \mathrm{~V}$. The pulses generated by the proximity switch were passed to the DAQ through the same means as for the FCO318 pressure transmitter and generator voltage outputs. Synchronous measurements of output power, rotor speed and tunnel wind speed could therefore be obtained.

The power output was calculated in the DAQ software by processing the instantaneous reading of generator output voltage, sampled at a rate of $250 \mathrm{~Hz}$ over a period of 1 second, to give a root-mean-squared voltage, which was then combined with the total resistance of the load to give the root-mean-square power output. In the calculation of power coefficient, $C_{P}$, the blade swept area was used as the reference area.

During each test the T7 tunnel was switched on at its minimum operating velocity and the wind speed was then increased in steps of $\Delta U$ of $0.25 \mathrm{~m} / \mathrm{s}$ until autorotation of the turbine was initiated. The turbine was then allowed to idle at this cut-in wind speed for a period of 10 minutes, so as to allow the generator's output to stabilise. Such an approach was based on a series of preliminary tests with the generator that indicated its voltage output varied slightly with time due to increasing temperature, but that this effect was limited by air cooling the generator coil.

At the end of the initial stabilising period, the tunnel speed was then increased in steps of approximately $0.5 \mathrm{~m} / \mathrm{s}$ until the maximum wind speed of no more than $14 \mathrm{~m} / \mathrm{s}$ was achieved. At each new wind speed the turbine was allowed to stabilise for a period of $60 \mathrm{~s}$ before measurements were recorded for a period of $30 \mathrm{~s}$. Throughout each of these $30 \mathrm{~s}$ data logging periods continuous readings of the voltage output and tunnel speed were sampled at a rate of $250 \mathrm{~Hz}$. A buffer size of $1 \mathrm{~s}$ was used in measuring turbine performance, so that readings of the rotational frequency were effectively made only once every second. The root-mean-square voltage, and hence the output power, were also assessed at 1 second intervals. Once the maximum wind speed was reached the tunnel speed was then reduced in steps of $1.0 \mathrm{~m} / \mathrm{s}$ until the point at which the turbine stopped auto-rotating was reached, ie: at the cut-off wind speed. Experiments were performed for the turbine with blade sets with and without passive air jets, and for different blade pitch settings, $\delta$, where the default blade pitch setting was regarded as $\delta=0^{\circ}$. This corresponded with a root aerofoil geometric pitch setting of $-25^{\circ}$ from the vertical rotor plane and the tip set to $-10^{\circ}$. Each experiment was repeated three times for consistency.

\subsection{Results from the wind turbine study}

The measured variation of power output with wind speed, for the turbine with baseline blades set a zero blade pitch, is plotted in figure 6 for four separate tests. The data shows that the power curves are completely repeatable, within the experimental measurement accuracy. Interestingly an effect of viscous hysteresis was identified, with the sudden spin-up of the turbine occurring at around $U=10 \mathrm{~m} / \mathrm{s}$, as the wind speed is increased, while the corresponding spin-down occurs at the lower $U=9 \mathrm{~m} / \mathrm{s}$ as the wind speed is reduced. This can be explained as the result of the flow over the blades being stalled along part of their span at low rotation rates, and that as the flow speed builds up, along with the local Reynolds number, the boundary layer suddenly 
attaches, the blade un-stalls and the blades spin up. The reverse process happens during the speed down of the wind tunnel, but the stall occurs at a lower wind speed because of the inherent energy in the boundary layers due to the higher circumferential velocity. If the passive air jet technology can be designed to allow the blades to un-stall earlier during tunnel speed acceleration, and/or stall later during the tunnel deceleration phase of the experiment, then real performance benefits could be achievable with the technology, as higher power yield might be possible at lower wind speeds, and the turbine might perform more effectively in gusty wind conditions.

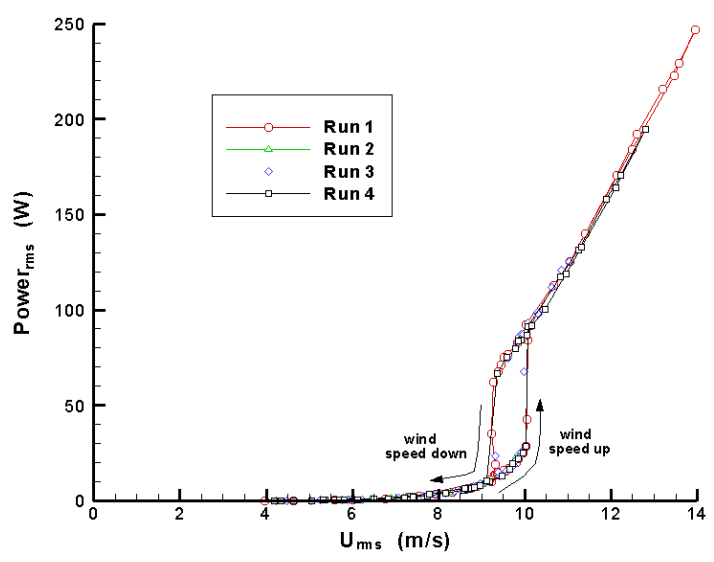

a) Power plotted against wind speed

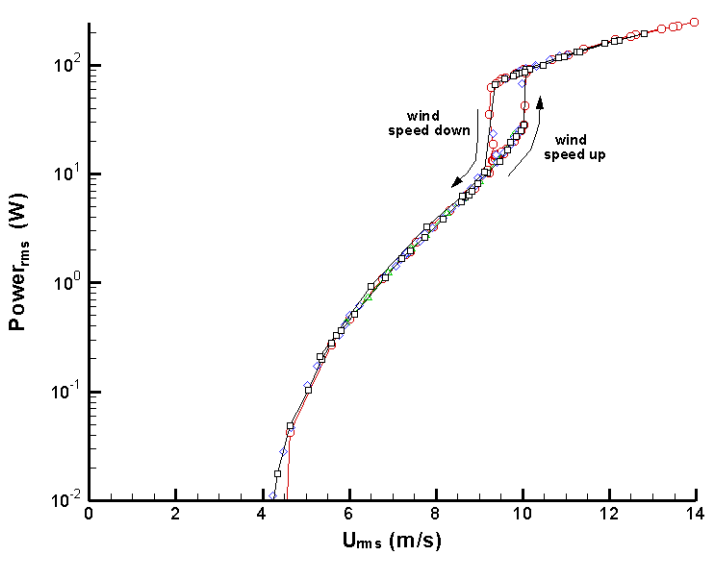

b) log of power plotted against wind speed

Figure 6: Repeatability of turbine power output for standard blade pitch $\left(\delta=0^{\circ}\right)$

Figure 7 presents the results of a series of tests to assess the sensitivity of the turbine to blade pitch angle, $\delta$. Tests were conducted with all six blades set at $+5^{\circ}$ and $-5^{\circ}$ blade pitch, and revealed considerable performance sensitivity to blade pitch. Figure 7 shows that increasing $\delta$ to $+5^{\circ}$ moves the cut-in wind speed from the baseline $\sim 4.2 \mathrm{~m} / \mathrm{s}$, to about $5.5 \mathrm{~m} / \mathrm{s}$, with the result that, at a given wind speed above cut-in, the power yield is considerably less than that generated with zero blade pitch. In addition, the spin-up wind speed was found to be delayed until $\sim 11.5 \mathrm{~m} / \mathrm{s}$, compared with around $10 \mathrm{~m} / \mathrm{s}$ with zero blade pitch. The un-stalled blades set at $\delta=+5^{\circ}$, were found to generate marginally more power for a given wind speed above spin-up. During wind speed deceleration the blade stalling event was found consistently to occur at $\sim 9.5 \mathrm{~m} / \mathrm{s}$, which is about $1 \mathrm{~m} / \mathrm{s}$ earlier than with zero blade pitch. The result is a much larger effect of aerodynamic hysteresis. Reducing the blade pitch angle to $\delta=-5^{\circ}$ resulted in a $0.2 \mathrm{~m} / \mathrm{s}$ reduction in the cut-in wind speed, and significantly higher power levels prior to the spin-up event. The unstalled blades set at $\delta=-5^{\circ}$, however, were found to generate significantly less power for a given wind speed, and there was no significant aerodynamic hysteresis effect seen in the data.

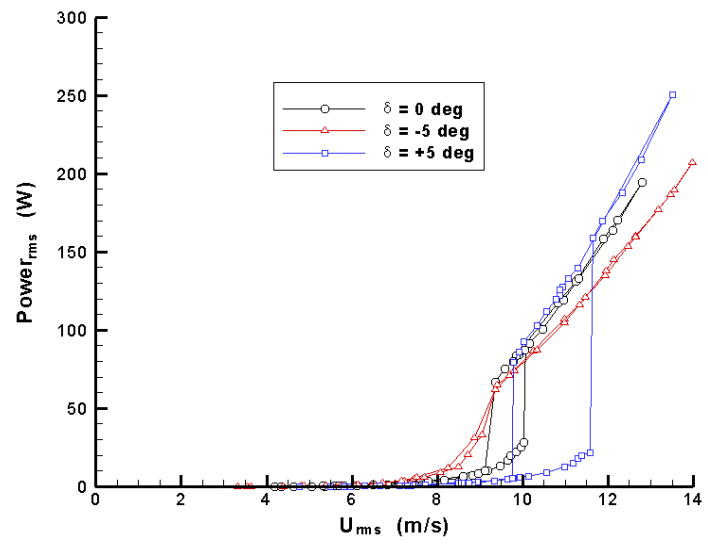

a) Power plotted against wind speed

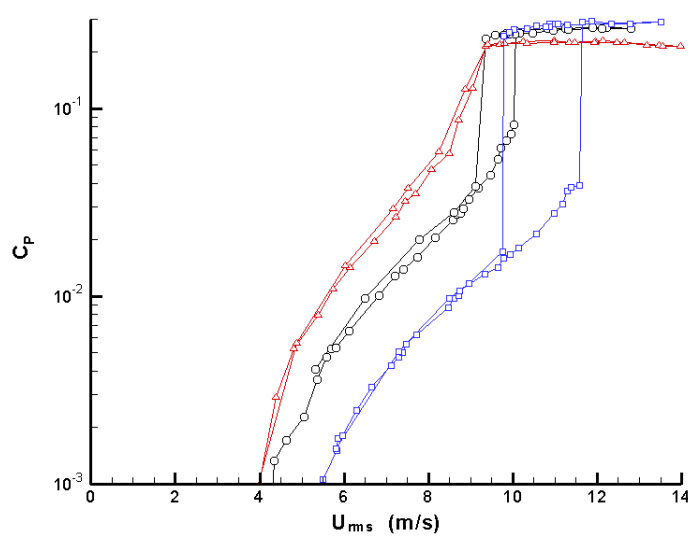

b) log of power plotted against wind speed

Figure 7: The effect of blade pitch setting for the clean bladed wind turbine 
Once the performance of the turbine with clean blades was established, the experiment was repeated with the six modified blades with air jets. Figures 8, 9 and 10 present the comparison of the turbine performance with, and without passive air jets, for blade pitch settings of zero, $-5^{\circ}$ and $+5^{\circ}$ respectively. For the zero pitch case, presented in figure 8 , the air jets were seen to reduce the cut-in wind speed by about $0.3-0.4 \mathrm{~m} / \mathrm{s}$ and deliver a small increase in power output prior to the spin-up event. The unstalled blades then provide marginally greater (about $3-5 \mathrm{~W}$ extra) power yield over the baseline levels for a given wind speed. During wind speed deceleration, the air jets were found to maintain attached flow performance to a wind speed of $8.2 \mathrm{~m} / \mathrm{s}, 0.8 \mathrm{~m} / \mathrm{s}$ lower than seen with the clean blades, resulting in a much wider power hysteresis loop. These results were found to be repeatable, and suggest that the passive air jets did, successfully, reduce cut-in wind speed and improve the performance of the stalled blades at lower wind speeds. However, only a marginal improvement in maximum power output was observed. In addition, the reduced wind speed at which the blades stalled, during wind speed deceleration, suggests that the air jets would also reduce turbine sensitivity to gusty wind conditions, allowing for higher average power output.

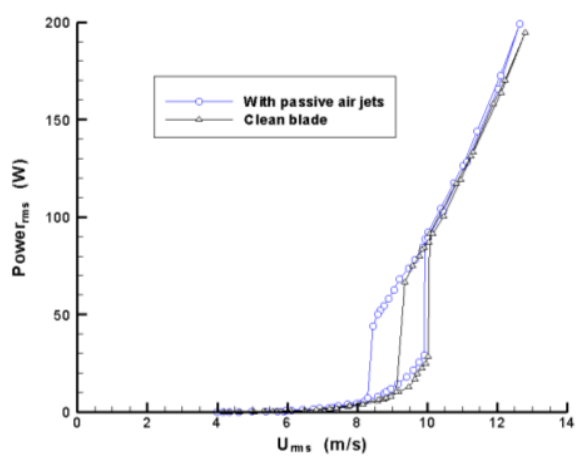

a) U versus output power

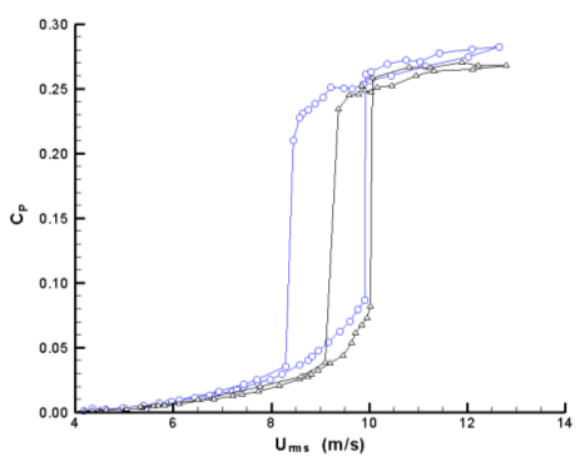

b) Uversus $C_{P}$

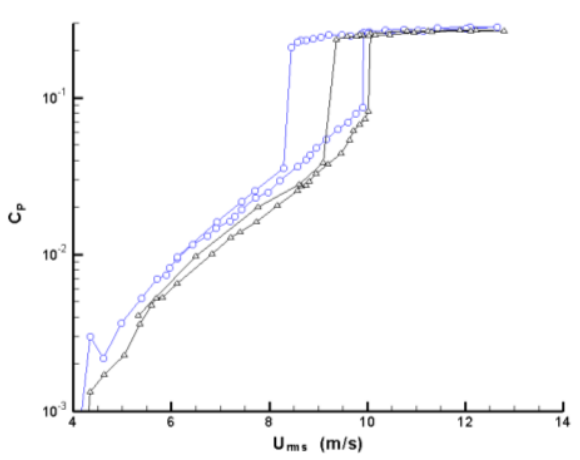

c) Uversus $\log _{10}\left(C_{P}\right)$

Figure 8: Comparison of wind speed versus power output for the clean bladed and passive air jet controlled turbines for zero blade pitch setting.

Similar results, presented in figure 9 , were found for the $\delta=-5^{\circ}$ pitch setting. The passive air jets introduced aerodynamic hysteresis effects into the power curves, where none existed for the clean blade case. The spin-up occurred at $\sim 0.5 \mathrm{~m} / \mathrm{s}$ lower wind speed than seen with clean blades, while the corresponding stall event during wind speed deceleration occurred at a speed $1 \mathrm{~m} / \mathrm{s}$ lower. A much extended range of wind speed giving high power output was therefore found possible with passive air jets, which would result in less sensitivity to gusts in atmospheric operation. However, a small reduction in maximum power coefficient, of less than 0.01 , was seen with the application of air jets at this blade setting.

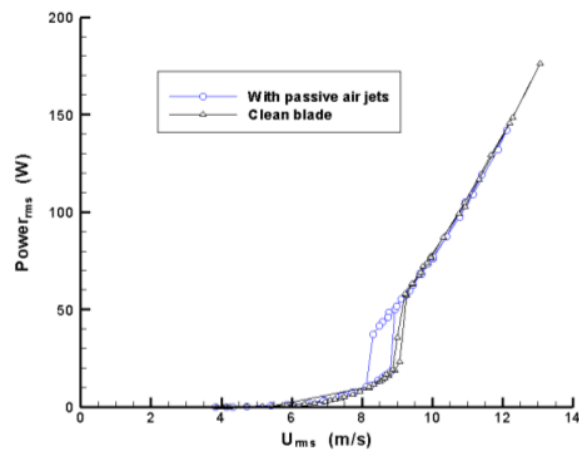

a) Uversus output power

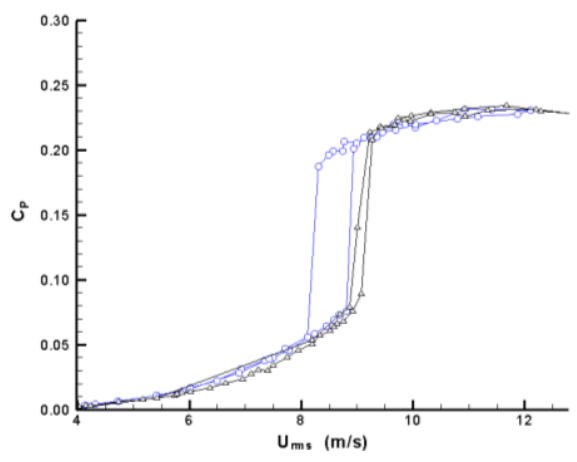

b) Uversus $C_{P}$

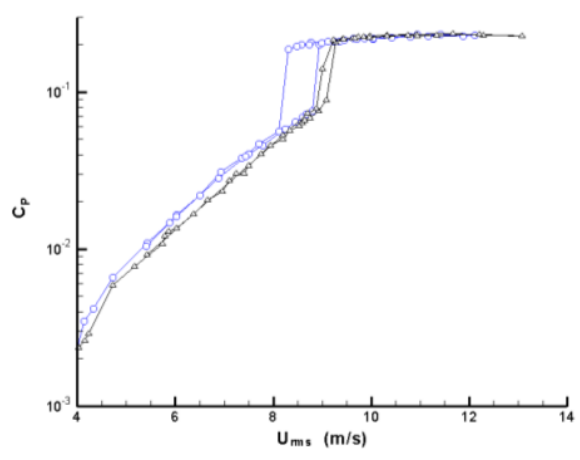

c) U versus $\log _{10}\left(C_{P}\right)$

Figure 9: Comparison of wind speed versus power output for the clean bladed and passive air jet controlled turbines for -5 blade pitch setting.

For the $\delta=+5^{\circ}$ pitch setting, the results for which are plotted in figure 10, the air jets are seen to delay the spin-up event to a wind speed $0.2 \mathrm{~m} / \mathrm{s}$ higher than that seen with the clean bladed turbine. This is a detrimental effect, and might be indicative of the air jets exacerbating an already chaotic separated flow field. The cut-in wind speed is not seen to be affected by the air jets, nor the power levels prior to the spin-up event. The only beneficial effects were found to be a slightly higher maximum power 
coefficient - an increase by 0.015 , at the highest wind speeds, and a $0.5 \mathrm{~m} / \mathrm{s}$ delay in the stalling wind speed during wind speed deceleration. This is consistent with the findings of previous studies of air jet vortex-generators, which have shown that they are much less able to reattach a flow that is significantly stalled, than one with only moderate levels of flow separation.

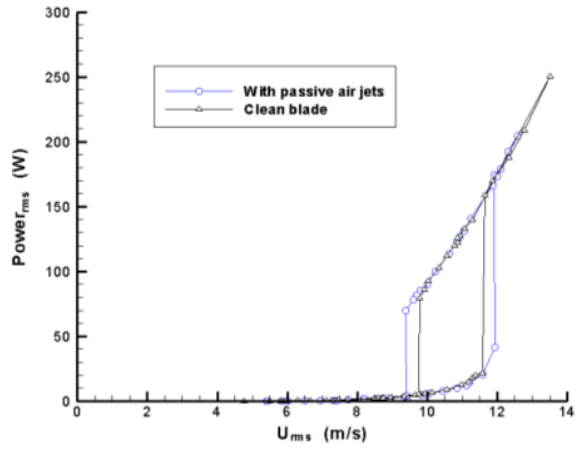

a) Uversus output power

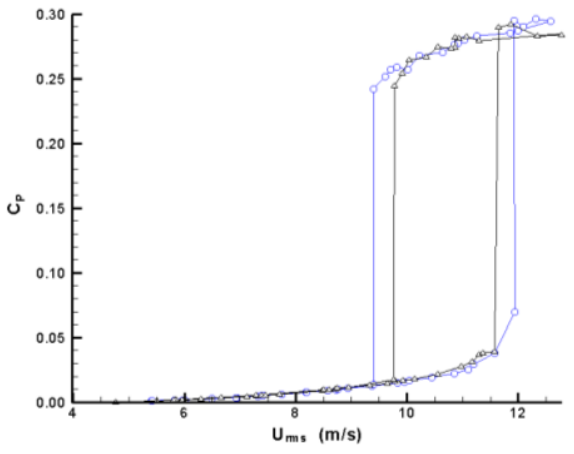

b) Uversus $C_{P}$

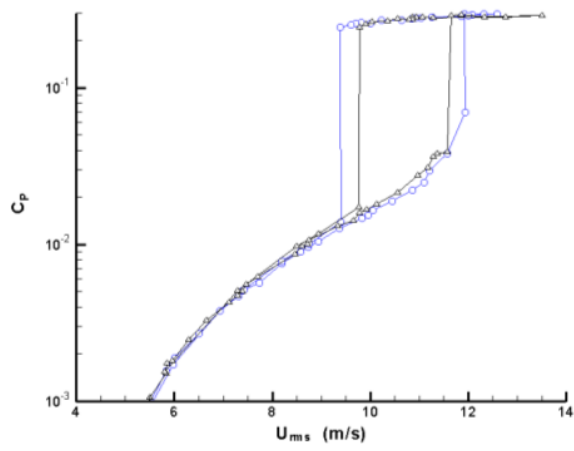

c) U versus $\log _{10}\left(C_{P}\right)$

Figure 10: Comparison of wind speed versus power output for the clean bladed and passive air jet controlled turbines for $+5^{\circ}$ blade pitch setting.

Figure 11 plots the variation of output power coefficient with averaged (rms) blade tip-speed to wind-speed ratio, $\lambda_{r m s}$, for the turbine with blade pitch set at zero, with and without passive AJVGs. Above $\lambda_{\text {rms }}$ of about 1, the passive air jet effect is seen to provide higher levels of power coefficient for a given tip-speed ratio, particularly at the higher tip-speed ratios. Maximum $C_{P}$ is seen to increase from a figure of 0.27 with clean blades, to 0.285 with blades with the passive AJVGs.

The hub and blade assembly with, and without the air jets, were both weighed on electronic scales in order to assess the level of mass reduction due to the drilled out material missing from the modified blades. This removal of material in implementing the air jets resulted in only $0.05 \%$ reduction in blade mass. The inertial effects, and the effect of any friction force changes in the generator due to the change in weight of the blade/hub assembly are not expected to have made any significant effect on the turbine performance, and it is suggested that the measured performance changes are genuinely aerodynamic in nature.

In summary, this experimental study applied to a small domestic wind turbine has demonstrated that simple passive air jet vortex-generators, properly designed and implemented, can provide worthwhile performance benefits for this class of turbine. The question remains as to whether such a flow control device could improve the performance, and similarly reduce the sensitivity of power output in gusty conditions, for an industrial scale stall regulated wind turbine. The next section aims to address the first part of this question by applying theoretical analysis to the performance prediction of a $500 \mathrm{~kW}$ wind turbine.

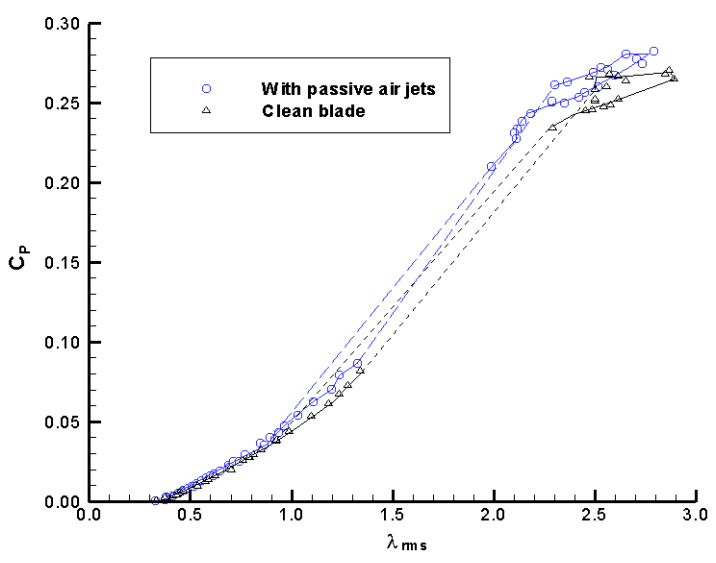

Figure 11: Comparison of tip speed ratio versus power coefficient for the clean bladed and passive air jet controlled turbines at zero blade pitch setting. 


\section{THEORETICAL ASSESSMENT OF PASSIVE AIR JET VORTEX-GENERATORS ON AN INDUSTRIAL SCALE HORIZONTAL AXIS WIND TURBINE}

A computer code implementing blade element momentum theory (BEMT) was written in order to estimate the effect of passive air jet vortex-generators applied to an industrial scale wind turbine. The code incorporated the tip loss model of Prandtl, described by Glauert ${ }^{35}$ and the Glauert correction for high levels of axial induction ${ }^{35,36}$, but the 3D effects associated with viscosity, such as the Himmelskamp effects ${ }^{37}$, and dynamic stall, were not deemed to be of importance to this simple analysis, which assumed steady wind with no cross-flow component. The blades were also assumed to be rigid. This analysis, while only using simple momentum principles and 2D flow assumption is, nevertheless, expected to resolve the overall effect of the flow control devices, and provide a reasonably accurate assessment as to the level of performance benefit achieved by their use.

The Nordtank NTK 500/41, 500 kW rated, wind turbine at Risø National Laboratory in Denmark, was chosen as the test case for this study since there is a significant amount of published performance data. The details of the design and operation of this turbine, and the experimental performance data obtained from it since 1995 is presented in references ${ }^{38-40}$. In summary, the turbine is a stall regulated, fixed pitch design, with 3 blades (LM 19.1) of $41 \mathrm{~m}$ swept diameter. Its hub height is $35 \mathrm{~m}$ above the ground. The turbine is operated at a fixed rotational speed of $27.1 \mathrm{rpm}$. with a cut-in wind speed of $4 \mathrm{~m} / \mathrm{s}$ and a cut-out wind speed of $25 \mathrm{~m} / \mathrm{s}$. The blades, whose planform and profiles are detailed in references $24-26$, have FFA-W3-xxx series aerofoil sections (30\% thickness at $8 \mathrm{~m}$ span to $24 \%$ at $10 \mathrm{~m}$ span) inboard, and NACA $63-4 \mathrm{xx}$ sections (18\% thickness at $12.5 \mathrm{~m}$ span to $16.5 \%$ at $16.5 \mathrm{~m}$ span) outboard, with chord length reducing from $1.63 \mathrm{~m}$ at $4.5 \mathrm{~m}$ span, to $0.265 \mathrm{~m}$ at the tip. Blade twist angle (relative to the blade tip) was 20 degrees at the $4.5 \mathrm{~m}$ span station.

Two dimensional aerodynamic data tables for $C_{L}$ and $C_{D}$, over the incidence range $-90^{\circ}<\alpha<+90^{\circ}$, were constructed for both the FFA W3 sections and the NACA 63-4xx section, with the aid of data presented in references 40 and 41 . The BEMT code used 2D data for four aerofoils according to an input file providing details of twist, chord and aerofoil geometry at the centre of a set number of spanwise elements. Baseline (no flow control effects) calculations were performed for the case of 16,24 and 32 spanwise elements along the blade. The resulting output power and blade loading predictions with 24 elements were within 5\% of the figures obtained using just 16 elements, but showed no significant difference with the figures given with 32 elements along the blade. The analysis was therefore undertaken using 32 elements to define the blade geometry and associated aerodynamic loading.

Figure 12 presents the comparison between the experimentally measured, and BEMT predicted variation of output power and the associated power coefficient, with steady wind speed (inverse tip speed ratio for $C_{P}$ ) for the baseline Nordtank NTK 500/41 turbine. The time averaged power output is plotted, along with the curves indicating the maximum and minimum instantaneous power measured at the given average wind speed. The agreement between the BEMT predictions and the measured data appears to be very good up to an average wind speed of $15 \mathrm{~m} / \mathrm{s}$, beyond which the average experimental power output rises about $5 \%$ above the values predicted by simple BEMT, before agreement is, again, within $1 \%$ at wind speeds of $19-20 \mathrm{~m} / \mathrm{s}$. This underprediction of BEMT could be associated with the effects described by Himmelskamp ${ }^{37}$ where the radial outflow along the blade induces a Coriolis force in the chordwise direction, which imposes a favourable pressure gradient that will tend to delay boundary layer separation and subsequent stall. Despite this, it is suggested that the BEMT model predicted the power output to sufficient accuracy over most of the wind speed range that it is good enough to be able to predict the overall effect of the application of passive air jet vortex-generators to sufficient accuracy for this assessment.

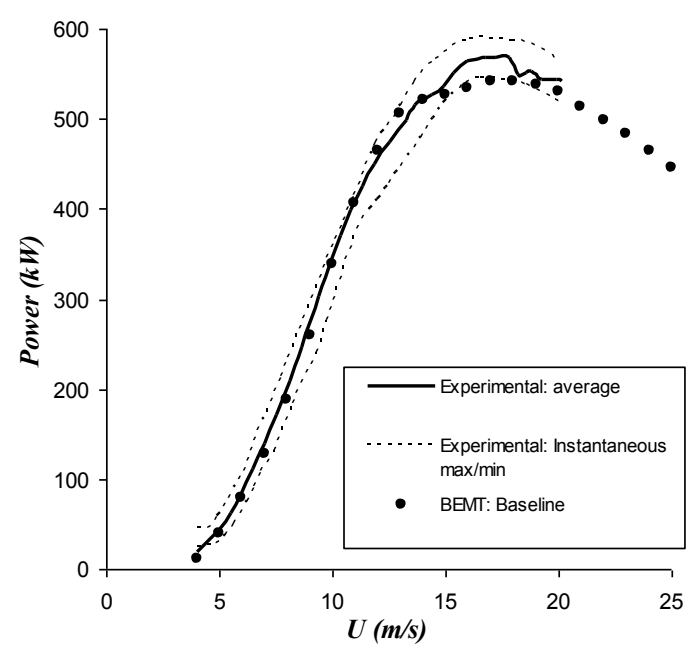

a) Power output versus wind speed

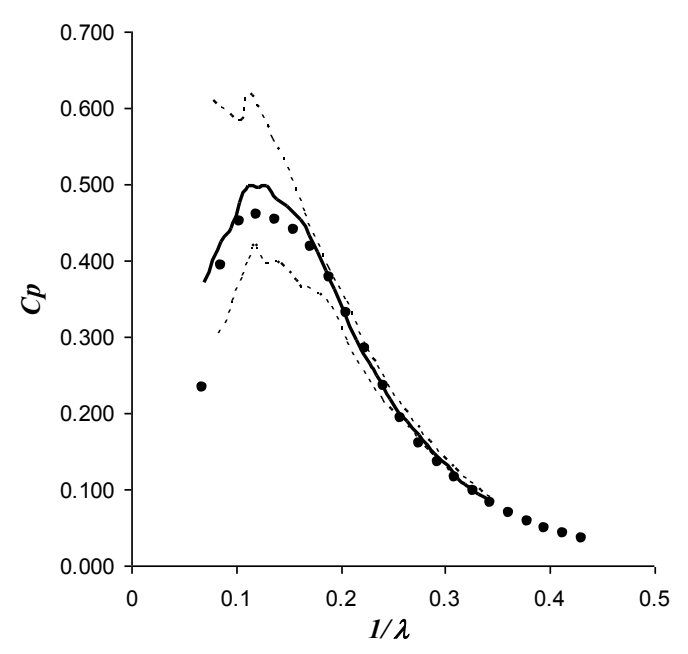

b) Power coefficient versus inverse tip speed ratio

Figure 12: Comparison between experimentally measured and theoretical prediction (blade element momentum theory) for the baseline Nordtank NTK 500/41 wind turbine. 
It is expected that on a rotating blade in real unsteady airflow conditions with spanwise flow, the actual performance improvement achievable will be somewhat less than achievable in quasi-2D flow as demonstrated in section 3 . It was therefore decided, for the purposes of this analysis, to assume an increase in $C_{L \max }$ of only $5 \%$, coupled with a $2^{\circ}$ delay in the angle-ofattack at which drag force divergence occurs. The $C_{L}$ and $C_{D}$ aerodynamic data tables were modified accordingly, whereby the linear portion of the $C_{L}$ versus $\alpha$ curve was extended to achieve a $5 \%$ increase in $C_{L m a x}$ while the pre-stall trend in $C_{D}$ versus $\alpha$ was extended by an extra $2^{\circ}$ angle-of-attack. The post-stall $C_{L}$ and $C_{D}$ values were kept at the same magnitude as the baseline data. The BEMT calculations were repeated using the modified aerodynamic data tables to obtain turbine performance predictions incorporating the estimated effects of the passive air jets. Three spanwise configurations of air jets were modelled, the first with the air jet effect imposed across the entire span of the blade, the second with the air jet effect imposed only along the inboard 50\% span, and the third with the air jet effect imposed only along the outboard 50\% of the span. The resulting power output comparisons are presented in figure 13.

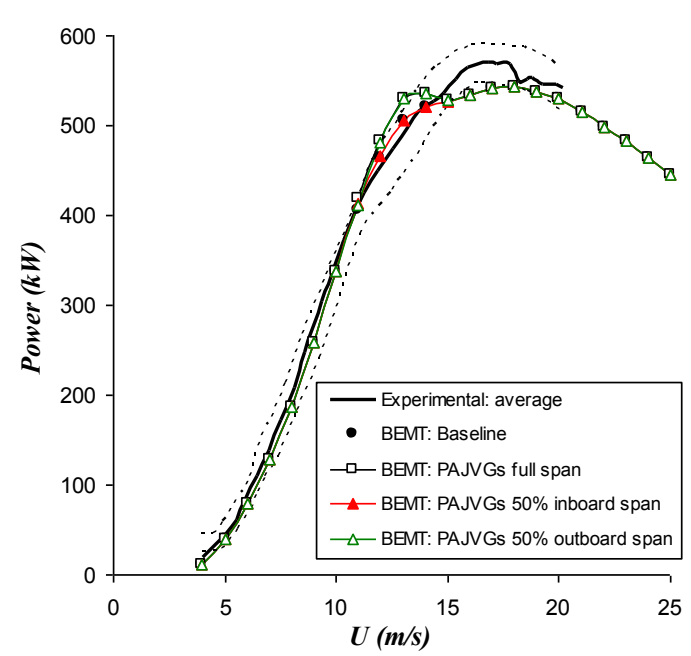

a) Power output versus wind speed

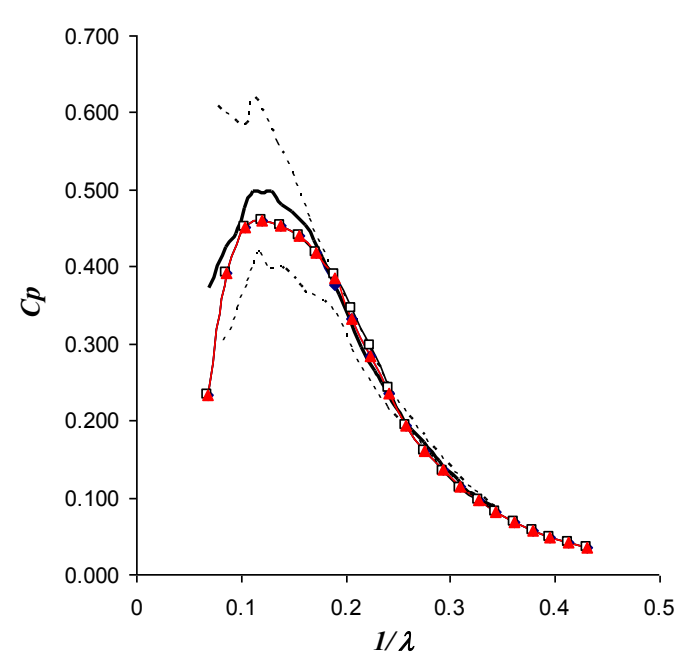

b) Power coefficient versus inverse tip speed ratio

Figure 13: Estimated effect, on turbine performance, of passive air jets applied to the Nordtank NTK 500/41 wind turbine for three spanwise air jet configurations.

Close scrutiny of the data shows that the predicted turbine output power is not affected at all be introducing the passive air jet effect up until an average wind speed of $10 \mathrm{~m} / \mathrm{s}$. Similarly there is no improvement in the level of $C_{P}$ for the lower tip-speed ratios. This is to be expected if there is no boundary layer separation at all, anywhere along the span of the blade. For the cases of the air jet effect applied across the full span, and of the air jets modelled on the outboard 50\% of the span of the blade, the power output curves are practically the same for $U>11 \mathrm{~m} / \mathrm{s}$. In both cases predicted power output is improved over the wind speed range $11>U>14 \mathrm{~m} / \mathrm{s}$. The loss in power output, from the expected attached flow trend, is predicted to be completely recovered up to a wind speed of $U=13 \mathrm{~m} / \mathrm{s}$. For wind speeds higher than $14 \mathrm{~m} / \mathrm{s}$ predicted power output levels remain unchanged. For the case of the air jet effect modelled along the inboard $50 \%$ of blade span, almost no improvement in power output level was predicted over the wind speed range $11>U>14 \mathrm{~m} / \mathrm{s}$.

The results of this simple study, based on a BEMT model of the Nordtank NTK 500/41 wind turbine, suggests that passive air jets would be able to recover some of the performance degradations that occur due to blade stall at intermediate wind speeds, prior to when rated power is achieved. Their effect would therefore be very similar to that of traditional vane vortex-generators, but with the added benefit of a much reduced excrescence drag penalty. In other words, passive air jet vortex-generators could effectively allow baseline stall regulated wind turbines to achieve rated power output at reduced wind speeds. It is also suggested that they could also help reduce turbine sensitivity to gusty wind conditions, much in the same way as it was found in domestic wind turbine study presented in section 4.

\section{CONCLUSIONS}

The conclusions derived from this study are as follows:

- The passive air jet vortex-generator has been shown to be able to suppress the onset of trailing edge separation from single element aerofoils tested in wind tunnel experiments. They are known to act in the same manner as actively blown air jets, by enhancing boundary layer mixing and thereby re-energizing the boundary layer. A $14 \%$ increase in $\mathrm{C}_{\mathrm{Lmax}}$ and a corresponding delay in drag rise of $2^{\circ}$ angle-of-attack was observed with a NACA23012C aerofoil model at 
$35 \mathrm{~m} / \mathrm{s}$, while a $9 \%$ increase in $\mathrm{C}_{\mathrm{Lmax}}$ and a $3^{\circ}$ angle-of-attack delay in drag rise was seen with a NACA $63_{2} 217$ aerofoil model at $25 \mathrm{~m} / \mathrm{s}$.

- Tests of these devices on a $0.87 \mathrm{~m}$ swept diameter, 6 bladed, domestic wind turbine revealed that they can slightly increase the maximum output power coefficient, reduce the cut-in wind speed, thereby improving power output at the lower wind speeds, while reducing the sensitivity of power output in gusty conditions by allowing the blades to remain un-stalled for longer during wind speed deceleration.

- A theoretical performance analysis of a $500 \mathrm{~kW}$ stall regulated wind turbine, based on simple Blade Element Momentum Theory, indicates that passive air jet vortex-generators would be capable of recovering some of the power loss resulting stall, thereby allowing attainment of rated power output at slightly lower average wind speeds.

\section{REFERENCES}

1. Talyor D. H and Hoadley H. H, 'Application of vortex-generator mixing principle to diffusers' Report R-15064-5, United Aircraft corporation, East Hartford, CT, 1948.

2. Freestone, M. 'Preliminary tests at low speeds on the vorticity produced by air-jet vortex-generators', Research Memo Aero. 85/1, City University London, Feb. 1985.

3. Compton D. A and Johnston P 'Streamwise vortex production by pitched and skewed jets in a turbulent boundary layer' AIAA Journal. Vol. 30(3), pp640-647, 1992.

4. Innes, F., Pearcey, H.H., and Sykes, D.M., 'Improvements in the performance of a three element high lift system by the application of air jet vortex-generators', The Aeronautical Journal, Vol. 99, pp 265-274, 1995.

5. Oyler T E, Palmer W E, 'Exploratory investigation of pulsed blowing for boundary layer control' Report NR 72H-12, North American Rockwell corp. 1972.

6. Seifert A, Bachar T, Koss D, Shepshelovich M. and Wygnanski I, 'Oscillatory Blowing: A tool to delay boundary layer separation', AIAA Journal. Vol. 33(11), pp2052-2060, 1993.

7. Seifert A, Darabi, A and Wygnanski, I, 'Delay of airfoil stall by periodic excitation', J of Aricraft, Vol. 33(4), pp691-698, 1996.

8. McManus K R. and Magill J, 'Separation control in incompressible and compressible flow using pulsed jets', AIAA Paper 96-1948, June 1996.

9. Greenblatt D. and Wygnanski I. 'Dynamic stall control by oscillatory addition of momentum. Part 1: NACA 0015 Parametric study', AIAA J Aircraft 38(3) pp430-438, 2001.

10. Huang, L. S., Maestrello, L and Bryant. D., 'Separation control over an aerofoil at high angles-of-attack', AIAA Paper: 871261, 1987.

11.Erk, P. P. 'Separation control on post-stall aerofoil using acoustically generated perturbations', PhD Thesis, Technical University of Berlin, 1997.

12. Donovan J.F., Kral L.D. and Cary A.W., 'Active flow control applied to an aerofoil', AIAA Paper 98-0210, 1998.

13. Amitay M and Glezer A., 'Aerodynamic flow control of a thick aerofoil using the synthetic jet actuators', Proceedings of the 3rd ASME/JSME Joint Fluids Engineering Conference, San Francisco, California, 1999.

14. Lorber, P., McCormick, D., Anderson, T., Wake, B., MacMartin, D., Pollack, M., Corke, T and Breuer, K., 'Rotorcraft retreating blade stall control', AIAA paper 2000-2475, 2000.

15. Gilarranz J.L and Rediniotis O. K., 'Compact, high-power synthetic jet actuators for flow separation control', AIAA paper 2001-0737, 2001.

16. 'Mod-2 Wind turbine system development final report, Vol. II Detailed report' NASA CR-168007, DOE/NASA/0002-82/2, 1982.

17. Sullivan, T.S. 'Effect of vortex-generators on the power conversion performance and structural dynamic loads of the Mod-2 wind turbine' NASA TM-83680, DOE/NASA/20320-59, 1984.

18. Corrigan, R.D. and Savino, J.M. 'Vortex-generators as a means for increasing rotor performance' Proc. 20th. Inter-soc. Energy Conversion Engineering Conf., Vol.3, pp.3.663-3.668, Miami, USA. 1985.

19. Gyatt, G.W. 'Development and testing of vortex-generators for small horizontal axis wind turbines' NASA CR-179514, 1986.

20. Garrad, A.D. 'The use of vortex-generators to improve wind turbine performance' Report 135/R/1, Garrad Hassan and Partners, Bristol, England, 1985

21. Afjeh, A.A., Keith, T.G. and Ardeshir, F. 'Predicted aerodynamic performance of a horizontal axis wind turbine equipped with vortex-generators' Journal of Wind Engineering and Industrial Aerodynamics, Vol. 33, pp. 515 -529, 1990.

22. Nyland, T.W. 'Surface pressure measurements on the blade of an operating Mod-2 wind turbine with and without vortexgenerators' NASA TM-83680, 1987.

23. Øye, S. 'The effect of vortex-generators on the performance of the Elkraft 1000kW turbine' Proc. 9th. IEA symposium on the aerodynamics of wind turbines, Stockholm, 1995. 
24. Antoniou, I., Petersen, S., Øye, S.,Westergaard, C.,Raben, N. and Jensen, F. 'The Elkraft 1MW wind turbine: Results from the test program' Proc. European Wind Energy Conference., Gothenburg, Sweden, 1996.

25. Wallis, .R A., 'The use of air jets for boundary layer control', Aeronautical Research Laboratories, Australia, Aero. Note no$110,1952$.

26. Oliver, A.G. 'Use of air jet vortex-generators to improve the L/D ratio of the NACA 63-2xx section, leading to improved power capture of the Ecotecnia 20/150 machine'. 8th. IEA symposium on the aerodynamics of wind turbines, Lyngby, Denmark, 1994.

27. Oliver, A.G., Wootton, L.R.W. and Prats, J. 'Use of air jet vortex-generators leading to improved energy capture and power regulation of a stall regulated wind turbine'. Proc. 18th. BWEA wind energy conference, Exeter, England, pp 61 -68, 1996.

28. Oliver, A. G. 'Air Jet Vortex-generators for Wind Turbines'. PhD Thesis, City University London, 1997

29. Vronsky, T. 'High Performance Cost-Effective Large Wind Turbine Blades Using Air-Jet Vortex-generators' ETSU Report $\mathrm{W} / 41$ / 00541.2000.

30. Prince, S. A., Khodagolian, V., Singh, C., Mour, S. and Kokkalis, A. 'Aerodynamic Stall Suppression On Aerofoil Sections Using Passive Air Jet Vortex-generators'. ICAS Paper 2008-3.11.3, $26^{\text {th }}$ International Congress of the Aeronautical Sciences, Anchorage, Alaska, September 2008.

31. S. A. Prince, V. Khodagolian, C. Singh \& T. Kokkalis 'Aerodynamic Stall Suppression on Aerofoil Sections Using Passive Air Jet Vortex-generators'. AIAA Journal Vol. 47. No. 9, 2009.

32. Krzysiak, A. 'Control of flow separation using self-supplying air-jet vortex-generators', AIAA Journal, Vol. 46, No. 9, 2008.

33. Green, R. B. and Galbraith, R. A. McD, 'Dynamic recovery to fully attached aerofoil flow from deep stall' AIAA Journal, Vol.33, No. 8, 1995.

34. Jones, B. Melville. 'The Measurement of Profile Drag by the Pitot-Traverse Method'. Aeronautical Research Council (ARC) R \& M No. 1688. January 1936.

35. Glauert, H. “Airplane Propellors” In Durand, W. F. (ed.), Aerodynamic Theory, Vol. 4, Division L, pp 169-360. Dover Publications, Inc., New York, 1935.

36. Glauert, H. "A General Theory of the Autogyro" ARCR R \& M No. 1111., 1926.

37. Himmelskamp, H., "Profile investigations on a rotation airscrew", Ph.D. Dissertation, Göttingen, 1945.

38. Paulsen, U.S., ’Konceptundersøgelse Nordtank NTK 500/41. Strukturelle laste (In Danish)”, Risø-I-936(DA), Risø National Laboratory, Roskilde, Denmark. November 1995.

39. Martin O. L. Hansen "Aerodynamics of the Wind Turbine”, James \& James, London 2000.

40. Christian Bak, Peter Fuglsang, Niels N. Sørensen, Helge Aagaard Madsen, Wen Zhong Shen \& Jens Nørkær Sørensen, “Airfoil Characteristics for Wind Turbines” Risø Report R-1065(EN), Risø National Laboratory, Roskilde, March 1999.

41. Bertagnolio, F., Sørensen, N.N., Johansen, J., \& Fuglasang, P. "Wind Turbine Airfoil Catalogue”, Risø-R-1280(EN), Risø National Laboratory, Roskilde, Denmark. August 2001. 
2016-05-16

The application of passive air jet

vortex-generators to stall suppression

on wind turbine blades

Prince, Simon A.

Wiley

Prince SA, Badalamenti C, Regas C, The Application of Passive Air Jet Vortex-generators to Stall Suppression on Wind Turbine Blades, Wind Energy, Volume 20, Issue 1, January 2017 , pÿPages 109123

http://dx.doi.org/10.1002/we.1994

Downloaded from Cranfield Library Services E-Repository 